BMJ Open Sport \& Exercise Medicine

\section{Impact of a structured, group-based running programme on clinical, cognitive and social function in youth and adults with complex mood disorders: a 12-week pilot study}

To cite: Keating LE, Becker S, McCabe K, et al. Impact of a structured, group-based running programme on clinical, cognitive and social function in youth and adults with complex mood disorders: a 12-week pilot study. BMJ Open Sport \& Exercise Medicine 2019;5:e000521. doi:10.1136/ bmjsem-2019-000521

Accepted 23 April 2019

Check for updates

(C) Author(s) (or their employer(s)) 2019. Re-use permitted under CC BY-NC. No commercial re-use. See rights and permissions. Published by BMJ.

${ }^{1}$ Neuroscience Graduate Program, McMaster University, Burlington, Ontario, Canada ${ }^{2}$ Psychology, Neuroscience and Behaviour, McMaster University, Hamilton, Ontario, Canada ${ }^{3}$ Mood Disorders Program, St Joseph's Healthcare Hamilton, Hamilton, Ontario, Canada ${ }^{4}$ Psychiatry and Behavioural Neurosciences, McMaster University, Hamilton, Ontario, Canada

${ }^{5}$ Research Administration, St Joseph's Healthcare Hamilton, Hamilton, Ontario, Canada ${ }^{6}$ Child and Adolescent Psychiatry, St Joseph's Healthcare Hamilton, Hamilton, Ontario, Canada

Correspondence to Dr Margaret C McKinnon; mmckinno@stjosham.on.ca

\section{ABSTRACT}

Background Individuals with mood disorders often report lingering health-related quality of life (HRQOL) and social and cognitive impairments even after mood symptoms have improved. Exercise programmes improve mood symptoms in patients, but whether exercise improves functional outcomes in patients with difficult-totreat mood disorders remains unknown.

Design We evaluated the impact of a 12-week structured running programme on cognitive, social and quality-oflife outcomes in participants with difficult-to-treat mood disorders.

Methods In a prospective, open-label study, patients referred to the St Joseph's Healthcare Hamilton Team Unbreakable running programme for youth and adults with mood disorders completed a comprehensive assessment battery before and after the 12-week exercise intervention. Results We collected preintervention and postintervention data from 18 participants who improved on the general health, vitality, role of emotions, social functioning and mental health (all $\mathrm{p} \leq 0.01$ ) HRQOL subscales. Performance improved on cognitive tests that assessed working memory and processing speed $(p \leq 0.04)$; there were no improvements in complex executive functioning tasks. Regression analyses indicated that younger age, shorter illness duration and reduced bodily pain predicted social and cognitive outcomes.

Conclusion Participation in a group-based, structured running programme was associated with improved HRQOL and social and cognitive function.

\section{BACKGROUND}

Mood disorders, including major depressive disorder (MDD) and bipolar disorder (BD), are a prevalent and costly social and health issue, affecting more than 300 million people worldwide. ${ }^{1}$ Twelve-month prevalence rates in Canada have been reported at $4.7 \%$ for $\mathrm{MDD}^{2}$ and up to $1.5 \%$ for $\mathrm{BD}^{2}{ }^{3}$ Indeed, the social, health and economic burdens of mood disorders have prompted the WHO to identify depression as the leading cause of ill

\section{Key messages}

We observed improved social and cognitive functioning in youth and adults with complex mood disorders characterised by high rates of comorbid diagnoses, ongoing functional impairments and high relapse rates who participated in a group-based, structured running programme.

- Participants reported improved health-related quality of life on subscales assessing physical and mental health.

- Younger age, shorter illness duration and reduced bodily pain predicted improved social and cognitive outcomes.

health and disability worldwide, calling for new management strategies. ${ }^{4}$

The social, health and economic burdens of mood disorders are in keeping with poor responses to treatment and high relapse rates observed over several decades. ${ }^{5-7}$ Whereas typical first-line treatments for mood symptoms include antidepressants and psychotherapy, ${ }^{8}$ mood stabilisers are the gold standard for managing symptoms of BD. ${ }^{6}$ Even patients who meet the criteria for remission following first-line treatment, however, frequently experience persistent mood, cognitive and social symptoms that impair functioning and quality of life in $\mathrm{MDD}^{10-12}$ and $\mathrm{BD} .{ }^{13}$ Thus, there is an urgent need to identify treatment strategies that improve short-term and long-term prognoses for patients with mood disorders across mood and functional outcomes. ${ }^{12} 14$

Several lines of evidence suggest that voluntary exercise may improve symptoms of mood disorders. In animals, voluntary exercise has been associated with improvements in anhedonia, ${ }^{15}$ anxiolytic behaviours ${ }^{16}$ and neurocognitive function. ${ }^{17}$ In humans, results have been less consistent, although 
a recent meta-analysis evaluating the effects of exercise on MDD symptoms found a significant effect of exercise across a variety of measures of depression. ${ }^{19}$ Critically, however, there is scant information concerning the effects of exercise on non-mood outcomes, including social and cognitive functioning and quality of life, in patients who do not respond to first-line therapies, ${ }^{20}$ or who experience recurrent episodes and ongoing functional impairment, ${ }^{121421}$ even after mood symptoms have improved. ${ }^{22}{ }^{23}$ Here, only a handful of studies reported improvements in depressive symptoms ${ }^{24-26}$ and psychosocial functioning and quality of life ${ }^{27}$ in treatment-resistant clinical populations. Finally, there is a paucity of research examining the impact of exercise on outcomes in patients with $\mathrm{BD} .{ }^{28}$ On balance, there is an urgent need for data concerning the relation between exercise and mood disorders: (1) across the spectrum of symptoms that include quality of life, cognitive functioning and social functioning; and (2) in difficult-to-treat forms of mood disorders with high burdens of illness. ${ }^{12}$

Since April 2012, a multidisciplinary clinical team in the Mood Disorders Program at St Joseph's Healthcare Hamilton (Hamilton, Ontario) has offered Team Unbreak$a b l e$, a 12-week recreational running programme. This group-based programme aims to provide therapeutic benefit to youth and adults with mood disorders, typically recruiting patients with complex clinical histories that have responded poorly to traditional treatments. A chart-based review of this sample previously confirmed a positive effect of running on symptoms of stress, anxiety and depression. ${ }^{29}$ Here, we report on a subset of these individuals who participated in a prospective study that evaluated the impact of this structured running programme on (1) health-related quality of life (HRQOL), (2) neurocognitive function and (3) social functioning outcomes.

\section{METHODS}

Data were collected from youth and adults who participated in the programme from August 2012 to December 2016.

\section{Participants}

Study participants were recruited from the Team Unbreakable group, who were recruited by posting flyers and sending information about the programme to clinics in and around St Joseph's Healthcare Hamilton sites. Depending on their age, participants joined either the youth (16-25 years) or adult ( $>25$ years) running group (see table 1). Inclusion criteria included history of mood disorder and ability to meet the physical demands of participating in the running programme. ${ }^{30}$ All eligible patients were invited to participate in the study. Those who agreed were required to sign informed consent forms prior to data collection. Clinical diagnoses were confirmed by reviewing formal assessments made by a psychiatrist or psychologist and documented on participants' medical records.

\section{Neurocognitive functioning assessments}

Neurocognitive functioning was assessed using a battery of tasks, including the following:

- California Verbal Learning Task-II (CVLT-II) ${ }^{31}$ : The CVLT-II assesses immediate and delayed memory performance, interference and recognition; an alternate version with different words was used for the end-of-study assessment.

- Wechsler Adult Intelligence Scale-Fourth Edition (WAISIV) Digit Span ${ }^{32}$ : The Digit Span task assesses working memory and attention, with increasing difficulty of the tests (forward, backward, sequencing) reflecting more complex levels of executive functioning. ${ }^{33}$

- Stroop Color-Word Task ${ }^{34}$ : The Stroop task measures different types of executive function, including cognitive flexibility and inhibition (colour-word task), as well as simple attention and processing speed (word and colour tasks).

Table 1 Sample demographics

\begin{tabular}{|c|c|c|c|c|}
\hline & Entire sample ( $\mathrm{N}=18)$ & Adult group $(n=6)$ & Youth group $(n=12)$ & $\begin{array}{l}\text { Adult compared with } \\
\text { youth }\end{array}$ \\
\hline \multicolumn{5}{|l|}{ Mean \pm SD (range) } \\
\hline Current age (years) & $30.2 \pm 15.4(16-62)$ & $48.8 \pm 13.8(30-62)$ & $21.2 \pm 2.4(16-25)$ & $t=4.9, d f=5.1, p=0.004$ \\
\hline Attendance & $60.3 \pm 25.4(8.3-91.2)$ & $67.5 \pm 13.4(50-87.5)$ & $56.4 \pm 29.7(8.3-91.2)$ & $t=0.9, d f=15, p=0.3$ \\
\hline Baseline BDI & $27.6 \pm 13.8(6-60)$ & $32.7 \pm 17.4(10-60)$ & $25.1 \pm 11.6(6-43)$ & $t=1.2, d f=16, p=0.3$ \\
\hline $\begin{array}{l}\text { Age at onset of mood } \\
\text { disorder }\end{array}$ & $23.4 \pm 14.0(13-61)$ & $37.0 \pm 18.4(14-61)$ & $16.5 \pm 2.3(13-22)$ & $t=2.7, d f=5.1, p=0.04$ \\
\hline $\begin{array}{l}\text { Duration of illness } \\
\text { (years) }\end{array}$ & $6.8 \pm 6.2(0-19)$ & $11.8 \pm 8.5(1-19)$ & $4.5 \pm 2.7(0-9)$ & $t=2.1, d f=5.5, p=0.08$ \\
\hline \multicolumn{5}{|l|}{ Proportion: n (\%) } \\
\hline Female participants & $16(88.9)$ & $6(100)$ & $10(83.3)$ & $\chi^{2}=1.1, d f=1, p=0.3$ \\
\hline
\end{tabular}

Significant results are shown in bold text.

BDI, Beck Depression Inventory. 
- Mnemonic Similarity Task (MST): This high interference memory task is a computer-based variant of the MST developed by Kirwan and Stark. ${ }^{35}$ During the study phase, a set of images are presented sequentially in randomised order to the participant. In the recognition phase, participants are shown a sequence of images and must decide whether each image is novel (not seen before), old (identical to the ones in the presentation stage) or similar (highly similar to a previously studied image).

Correct identification of similar images is a challenging memory test linked to hippocampal functioning. ${ }^{35}$ Specifically, performance on this type of high interference memory test is hypothesised to depend on hippocampal neurogenesis. ${ }^{36}$ MST performance is predicted by established modulators of neurogenesis in rodents, including binge drinking, stress and depression scores, ageing, and exercise. ${ }^{37-42}$ Importantly, evidence from rodent models links hippocampal neurogenesis directly to depression. ${ }^{43-46}$ Thus, the neurogenic theory of depression postulates that low neurogenesis levels increase vulnerability to depression, while restoration of neurogenesis levels is required to overcome depression. We therefore predicted that exercise would lead to improved MST performance in association with improved depression scores.

The following computer-based assessments were based on the Cambridge Neuropsychological Test Automated Battery (cambridgecognition.com/cantab) and coded in e-prime:

- Delayed match to sample: In each trial, the participant is shown a complex visual pattern (the sample) and, after a brief delay, four similar images with patterns. The participant must identify which image is identical to the sample image.

- Spatial recognition memory (SRM): The SRM tests visual spatial recognition memory involving a two-choice forced discrimination paradigm. During presentation trials, a white square appears sequentially at five different locations on the screen. During the recognition phase, five pairs of squares are presented; for each pair, the participant must correctly identify this square.

- Paired associate learning: This test assesses visuospatial associative memory and new learning. During the study phase, boxes are displayed on the screen and opened in a randomised order. One or more of them will contain a pattern. During the test phase, the patterns are displayed in the middle of the screen, and the participant must select the box where each pattern was originally located. If the participant makes an error, the trial is restarted.

- Rapid visual processing: In this test of sustained attention and working memory, a white box appears at the centre of the computer screen, inside which digits from 1 to 9 appear in a pseudorandom order at a rate of 100 digits per minute. Participants must detect target sequences of three successive digits (eg, 1-2-3) and register their response on the keyboard.

\section{Clinical assessments}

Clinical assessments included the following:

- Beck Depression Inventory-Second Edition (BDI-II; PsychCorp $)^{47}$ : a 21-item self-report questionnaire used to assess depressive symptoms.

- Beck Anxiety Inventory (PsychCorp) ${ }^{48}$ : a 21 -item self-report questionnaire used to assess the severity of an individual's symptoms of anxiety.

- Cohen's Perceived Stress Scale ${ }^{49}$ : a 10 -item self-report questionnaire used to measure the perception of stressful events during the past month.

- 36-Item Short Form Survey (SF-36) ${ }^{50}$ : $:$ a 36-item self-report assessment which measures HRQOL to generate eight scores in two domains. The physical domain includes physical functioning, limitations due to physical health, bodily pain and general health perceptions; the mental health domain assesses social functioning, mental health, limitations in physical activities due to emotions and vitality.

\section{Running protocol}

The running programme for this study has been described in detail previously. ${ }^{29}$ Briefly, the group met twice per week, alternating between walking and running. They increased total distance by about $0.5 \mathrm{~km}$ per run, and increased running intervals by $30-60 \mathrm{~s}$ per week. The goal was to be mostly running $5 \mathrm{~km}$ by week 12 , and then complete a local $5 \mathrm{~km}$ run as a group. The sessions were facilitated by running coaches (JW, KM), included weekly motivational talks across a range of topics, and engaged hospital staff and graduate students as running volunteers.

\section{Statistical analyses}

Preintervention and postintervention differences in continuous variables were analysed using paired t-tests; change scores were calculated as postintervention minus preintervention scores. Relations among variables of interest were evaluated using the Pearson correlation coefficient and multiple linear regression analyses. All analyses were performed using SAS V.9.4 for Windows.

\section{RESULTS}

Data were collected from 18 participants from August 2012 to December 2016 across 10 cohorts (see table 1). Although the youth group had an earlier age of onset and higher dropout rate than the adult group, previous analyses using a larger data set indicated no difference in youth compared with adult runners in terms of mood outcomes. ${ }^{29}$ Further, the rates of MDD and BD were similar in both groups $(71.4 \%$ and $14.2 \%$ compared with $81.8 \%$ and $9.1 \%$ for adult and youth groups, respectively); therefore, the groups were analysed together. There were fewer male than female participants $\left(\chi^{2}=11.8, \mathrm{df}=1\right.$, $\mathrm{p}=0.0006$ ), and eight participants completed baseline 
Table 2 Characteristics of study completers compared with dropouts

Completed preassessment Completed baseline only* and postassessment $(n=18) \quad(n=8)$

\begin{tabular}{|c|c|c|c|}
\hline \multicolumn{4}{|l|}{ Mean \pm SD (range) } \\
\hline Current age (years) & $30.2 \pm 15.6(16-62)$ & $23.6 \pm 4.0(18-31)$ & $t=-1.7, d f=21.3, p=0.11$ \\
\hline $\begin{array}{l}\text { Attendance (\% sessions } \\
\text { attended) }\end{array}$ & $60.3 \pm 25.3(8.3-91.2)$ & $30.9 \pm 25.8(8.3-83.3)$ & $t=-2.5, d f=22, p=0.02^{*}$ \\
\hline Baseline BDI & $27.6( \pm 13.8 ; 6-60)$ & $22.1( \pm 12.3 ; 0-49)$ & $t=-1.0, d f=24, p=0.3$ \\
\hline $\begin{array}{l}\text { Age at onset of mood disorder } \\
\text { (years) }\end{array}$ & $23.4 \pm 14.2(13-61)$ & $15.5 \pm 2.5(12-18)$ & $t=-2.5, d f=19.8, p=0.02^{*}$ \\
\hline Duration of illness (years) & $6.8 \pm 6.3(0-19)$ & $9.8 \pm 4.8(4-15)$ & $t=1.1, d f=22, p=0.3$ \\
\hline \multicolumn{4}{|l|}{ Proportion, n (\%) } \\
\hline Female participants & $16(89)$ & $6(75.0)$ & $\chi^{2}=0.8, d f=1, p=0.4$ \\
\hline Baseline diagnosis of MDD & $14(77.8)$ & $3(37.5)$ & $\chi^{2}=4.0, d f=1, p=0.05$ \\
\hline Baseline diagnosis of BD & $3(16.7)$ & $5(62.5)$ & $\chi^{2}=5.5, d f=1, p=0.01$ \\
\hline
\end{tabular}

*Participants did not necessarily drop out of the running group, but did not complete the end-of-study assessments.

BD, bipolar disorder; BDI, Beck Depression Inventory; MDD, major depressive disorder.

but not end-of-study assessments (table 2). Those who dropped out of the study were more likely to be male, have a primary diagnosis of $\mathrm{BD}$ and illness diagnosis in their teens compared with those who completed the end-of-study assessments. Baseline comorbid diagnoses included social anxiety disorder $(n=11)$, generalised anxiety disorder $(n=9)$, substance use/abuse $(n=5)$, agoraphobia $(n=2)$, panic disorder $(n=1)$, post-traumatic stress disorder $(n=1)$, dysthymia $(n=1)$ and psychotic symptoms $(n=3)$. Data presented in table 2 further illustrate the complex clinical histories of the participants. Comparison of those who participated in the prospective study compared with those who did not is presented in table 3; no significant differences were observed in age, baseline BDI, primary clinical diagnosis or number of comorbid diagnoses.

\section{Preintervention and postintervention assessments}

HRQOL results are summarised in table 4 . Whereas all of the mental health subscale scores (mental health, vitality, social functioning, role of emotions in functioning) improved significantly from baseline to end of study, of the physical health subscales only the general health subscale improved significantly from baseline.

Neurocognitive function

The results of the neuropsychological analyses are summarised in table 5. Only the WAIS Digit Span Forward (DSF) and the Stroop Color tests improved significantly from baseline compared with end of study, reflecting improved working memory and processing speed, respectively.

\section{Multiple linear regression analyses}

We predicted a priori that participation in a running group would be associated with improvements in cognitive $^{52}$ and social ${ }^{27}$ function. Therefore, we performed multiple regression analyses with the DSF and Stroop Color change scores as dependent variables for cognitive function and the SF-36 social function change score for social function. Predictor variables entered into the model were age, attendance, age at illness diagnosis,

Table 3 Running group participants who consented to be in the study compared to those who declined

\begin{tabular}{|c|c|c|c|}
\hline & Participants $(n=26)$ & Non-participants $(n=16)$ & $\begin{array}{l}\text { Participants compared } \\
\text { with non-participants }\end{array}$ \\
\hline \multicolumn{4}{|l|}{ Mean \pm SD (range) } \\
\hline Current age (years) & $27.9 \pm 13.7(16-62)$ & $32.4 \pm 15.5(17-62)$ & $t=0.9, d f=38, p=0.4$ \\
\hline Baseline BDI & $25.8 \pm 13.2(6-60)$ & $30.0 \pm 13.3(2-48)$ & $t=1.01, d f=40, p=0.3$ \\
\hline Comorbid diagnoses & $1.2 \pm 1.0(0-3)$ & $0.9 \pm 1.1(0-3)$ & $\mathrm{t}=-0.9, \mathrm{df}=47, \mathrm{p}=0.4$ \\
\hline \multicolumn{4}{|l|}{ Per cent of participants } \\
\hline Female & 85.2 & 62.5 & $\chi^{2}=2.9, d f=1, p=0.10$ \\
\hline Diagnosis of MDD & 65.4 & 73.9 & $\chi^{2}=0.4, d f=1, p=0.5$ \\
\hline Diagnosis of BD & 30.8 & 26.1 & $\chi^{2}=0.13, d f=1, p=0.7$ \\
\hline
\end{tabular}

BD, bipolar disorder; BDI, Beck Depression Inventory; MDD, major depressive disorder. 
Table 4 Health-related quality of life

\begin{tabular}{|c|c|c|c|}
\hline SF-36 subscale & Preintervention, mean $( \pm S D)$ & Postintervention, mean ( \pm SD) & Paired t-test \\
\hline Physical fitness & $78.0( \pm 20.4)$ & $84.3( \pm 16.7)$ & $t=-1.3, d f=17, p=0.2$ \\
\hline Role of physical & $51.3( \pm 34.0)$ & $62.5( \pm 38.5)$ & $t=-1.2, d f=17, p=0.2$ \\
\hline Bodily pain & $69.6( \pm 25.8)$ & $70.5( \pm 22.2)$ & $t=-0.2, d f=17, p=0.9$ \\
\hline General health & $52.5( \pm 17.5)$ & $61.3( \pm 13.5)$ & $t=-3,0, d f=17, p=0.007$ \\
\hline Vitality & $26.8( \pm 14.6)$ & $41.5( \pm 20.0)$ & $t=-2.9, d f=17, p=0.01$ \\
\hline Social functioning & $46.3( \pm 25.4)$ & $64.4( \pm 27.3)$ & $t=-3.1, d f=17, p=0.007$ \\
\hline Role of emotions & $11.7( \pm 19.6)$ & $41.7( \pm 41.7)$ & $t=-2.9, d f=17, p=0.009$ \\
\hline Mental health & $44.0( \pm 17.7)$ & $55.4( \pm 19.1)$ & $t=-3.0, d f=17, p=0.007$ \\
\hline
\end{tabular}

Significant results are shown in bold text.

SF-36, 36-Item Short Form Survey.

illness duration and SF-36 subscales (except for social functioning in the analysis for social function). The DSF change score was predicted by age of participant, where younger participants showed greater improvement from baseline to end of study (parameter estimate -0.06 ), explaining $34 \%$ of the variance $(F(1,17)=8.8, \mathrm{p}=0.009)$. The Stroop Color-only change score was predicted by shorter duration of illness (parameter estimate -0.6) and improved bodily pain scores (parameter estimate 0.2 ), explaining $41 \%$ of the variance $(F=4.8, \mathrm{df}=2,14, \mathrm{p}=0.03)$.

\begin{tabular}{|c|c|c|c|}
\hline Test & Preintervention (mean \pm SD) & Postintervention (mean \pm SD) & Paired t-test \\
\hline \multicolumn{4}{|l|}{ CVLT } \\
\hline Recall trials $1-5^{\star}$ & $53.2 \pm 7.6$ & $50.3 \pm 9.4$ & $\mathrm{t}=-1.4, \mathrm{df}=16, \mathrm{p}=0.2$ \\
\hline Short delay free recall* & $11.6 \pm 3.2$ & $12.1 \pm 2.8$ & $t=0.9, d f=16, p=0.4$ \\
\hline Short delay cued recall ${ }^{\star}$ & $12.2 \pm 2.2$ & $12.6 \pm 2.5$ & $t=1.1, d f=16, p=0.3$ \\
\hline Long delay free recall* & $12.2 \pm 3.4$ & $11.6 \pm 4.0$ & $t=0.6, d f=16, p=0.6$ \\
\hline Long delay cued recall ${ }^{\star}$ & $12.5 \pm 2.8$ & $12.6 \pm 2.5$ & $\mathrm{t}=-0.3, \mathrm{df}=16, \mathrm{p}=0.8$ \\
\hline Total repetitions $\dagger$ & $3.0 \pm 3.5$ & $1.4 \pm 1.6$ & $t=-1.8, d f=16, p=0.10$ \\
\hline Total intrusions $\dagger$ & $1.0 \pm 1.9$ & $0.7 \pm 1.7$ & $t=0.5, d f=15, p=0.6$ \\
\hline \multicolumn{4}{|l|}{ WAIS Digit Span } \\
\hline Total score ${ }^{\star}$ & $28.6 \pm 5.2$ & $29.8 \pm 6.0$ & $t=-1.6, d f=17, p=0.13$ \\
\hline Forward* & $10.7 \pm 2.6$ & $11.8 \pm 2.7$ & $t=-2.8, d f=17, p=0.01$ \\
\hline Backward* $^{*}$ & $8.7 \pm 2.4$ & $8.6 \pm 2.3$ & $t=-0.3, d f=17, p=0.8$ \\
\hline Sequential ${ }^{*}$ & $8.4 \pm 2.0$ & $8.6 \pm 2.5$ & $t=0.4, d f=17, p=0.8$ \\
\hline \multicolumn{4}{|l|}{ Stroop } \\
\hline Word $^{*}$ & $90.2 \pm 10.3$ & $90.5 \pm 12.2$ & $t=-0.2, d f=14, p=0.9$ \\
\hline Color & $67.2 \pm 10.7$ & $71.9 \pm 10.8$ & $t=-2.4, d f=14, p=0.04$ \\
\hline Color-Word interference* & $44.9 \pm 8.2$ & $46.3 \pm 10.4$ & $t=-1.0, d f=14, p=0.3$ \\
\hline $\begin{array}{l}\text { Delayed match to sample } \\
(\% \text { matches correct })^{\star}\end{array}$ & $86.0 \pm 5.4$ & $85.4 \pm 11.7$ & $t=-0.2, d f=10, p=0.8$ \\
\hline $\begin{array}{l}\text { Mnemonic similarity task } \\
\text { (\% similar correct) }^{*}\end{array}$ & $40.5 \pm 20.5$ & $44.9 \pm 20.1$ & $t=-1.1, d f=10, p=0.3$ \\
\hline $\begin{array}{l}\text { Spatial recognition memory } \\
(\% \text { matches correct })^{\star}\end{array}$ & $66.4 \pm 17.8$ & $68.2 \pm 14.7$ & $t=-0.5, d f=10, p=0.7$ \\
\hline $\begin{array}{l}\text { Paired associate learning } \\
\text { (number of trials) } \dagger\end{array}$ & $10.6 \pm 2.8$ & $10.3 \pm 2.7$ & $\mathrm{t}=0.3, \mathrm{df}=9, \mathrm{p}=0.8$ \\
\hline $\begin{array}{l}\text { Rapid visual processing } \\
(\% \text { correct })^{*}\end{array}$ & $88.4 \pm 13.2$ & $89.3 \pm 8.6$ & $\mathrm{t}=0.2, \mathrm{df}=6, \mathrm{p}=0.8$ \\
\hline
\end{tabular}

Significant results are shown in bold text.

${ }^{*}$ Higher scores indicate improvement.

CVLT, California Verbal Learning Task; WAIS, Wechsler Adult Intelligence Scale. 
Correlations with the Stroop Color-only change scores were $r=-0.5(p=0.04)$ and $r=0.4(p=0.1)$ for duration of illness and bodily pain change score, respectively.

\section{Social functioning}

Improved social functioning was predicted by improved physical functioning (parameter estimate $=0.4$ ) and higher attendance (parameter estimate $=0.33$ ), explaining $26 \%$ of the variance $(F(2,17)=2.9, \mathrm{p}=0.08)$. Correlations with social functioning were $\mathrm{r}=0.3(\mathrm{p}=0.2)$ for role of physical symptoms in functioning and $\mathrm{r}=0.4(\mathrm{p}=0.1)$ for attendance.

\section{Depression}

A stepwise multiple regression analysis was performed with BDI change score as the outcome variable, and age, attendance, age at illness diagnosis, duration of illness and SF-36 subscales as predictor variables (except mental health as this was highly correlated with BDI). Improved (negative) BDI scores were predicted by higher attendance (parameter estimate -0.13 ), improved bodily pain (parameter estimate -0.25 ), improved vitality (parameter estimate -0.26) and improved general health (parameter estimate 0.25$)$, accounting for $43 \%$ of the variance in BDI change scores $(F(3,15)=3.7, \mathrm{p}=0.04)$ (see figure 1$)$. Correlations with BDI change scores were attendance $(\mathrm{r}=-0.34, \mathrm{p}=0.15)$, bodily pain $(\mathrm{r}=-0.43, \mathrm{p}=0.05)$, vitality $(\mathrm{r}=-0.4, \mathrm{p}=0.06)$ and general health $(\mathrm{r}=-0.1, \mathrm{p}=0.8)$.

\section{DISCUSSION}

In a sample of youth and adults with mood disorders characterised by long duration of illness, recurrent episodes and/or multiple comorbidities, we observed pre-post improvement across multiple functional outcomes of mood disorders following participation in a 12-week running programme. Improvements were observed in the general physical health and all mental health subscales of the SF-36, including vitality, role of emotions in functioning, mental health and social functioning. Improved neurocognitive functioning was detected on measures of working memory and simple attention. Higher attendance was associated with improved social functioning and decreased depression scores, while a shorter duration of illness and improved bodily pain predicted improved processing speed in the Stroop Color test. Finally, participants with a primary diagnosis of $\mathrm{BD}$ and an earlier age of illness diagnosis were less likely to complete the study.

The neurocognitive improvements observed here are consistent with two recently published meta-analyses in healthy humans reporting small but significant effects of chronic exercise on working memory ${ }^{53}$ and attention and processing speed. ${ }^{52}$ Notably, both meta-analyses reported that older adults were more likely to show improvement, consistent with normal age-related decline. In the current study, improved scores on the DSF were predicted by younger age, suggesting room for improvement in younger participants with mood disorders, which may not be typical of a healthy, non-depressed sample. Further, contrary to findings in healthy young adults, ${ }^{384054}$ and to predictions made by the neurogenic theory of depression, ${ }^{43-46}$ we did not find an improvement on the MST task, believed to reflect hippocampal function and neurogenesis levels. This finding is consistent with meta-analyses reporting that duration of illness in depression predicts hippocampal volume $10 s s,{ }^{55-58}$ which may explain the lack of broader memory improvements in our participants, many of whom had been ill for many years. Further, a recent meta-analysis examining exercise and cognitive function in adults with depression reported no cognitive improvements across aerobic, anaerobic and mind-body interventions (eg, yoga) ${ }^{59}$ Indeed, literature reviews reveal considerable variability across studies investigating the impact of exercise on cognitive function outcomes (see Guiney and Machado, ${ }^{60}$ and Diamond ${ }^{61}$ ), possibly related to methodological differences across exercise programmes, clinical and demographic factors of participants, and neurocognitive assessment measures. ${ }^{52} 5359$ It is also noteworthy that the vast majority of research on exercise and cognitive functioning has been done in ageing samples, usually to investigate the effects of cognitive decline ${ }^{62}$; there is little information on the impact of exercise on memory in healthy young and middle-aged adults for comparison purposes. These inconsistencies underscore the need for further research into how clinical and demographic factors influence the neurocognitive benefits of exercise in participants with mood disorders.

In the current study, we observed improvements in general health and all mental health HRQOL subscales, which is consistent with the literature ${ }^{63-65}$ Further, the observed social functioning improvements build on our previously published finding of improved perceived friendship in an overlapping sample. ${ }^{29}$ To the best of our knowledge, this is the first study to report positive changes across multiple functional outcomes in a complex psychiatric sample of patients with mood disorders who, at baseline testing, were unemployed and/or struggling with school, had experienced multiple past episodes of depression, and were not being managed effectively by medications. Taken together, these findings support that participation in a group-based running programme positively impacts social functioning in youth and adults with mood disorders, ${ }^{1966}$ and may provide therapeutic benefit to patients with mood disorders who do not fully respond to first-line treatments.

\section{Limitations}

Although the results from the current study are encouraging, there are several limitations. First, in a large battery of cognitive tests, we observed significant improvements on two tasks (Stroop Color-only and DSF), and in both cases the changes were found on a less cognitively demanding subtest. Given the large number of tests administered, there is an elevated risk of a type I error rate; using a more conservative $p$ value of $\leq 0.01$, only the DSF subtask improved significantly. 
A

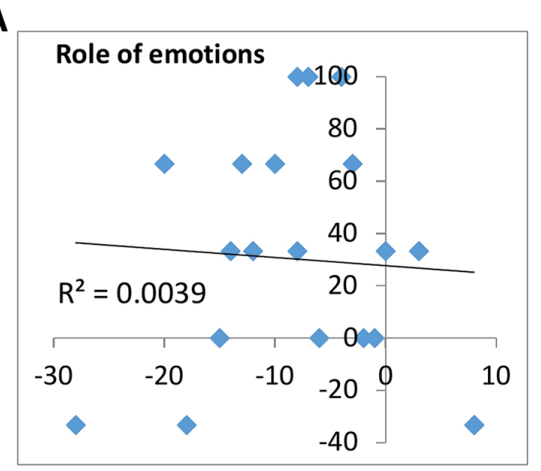

B

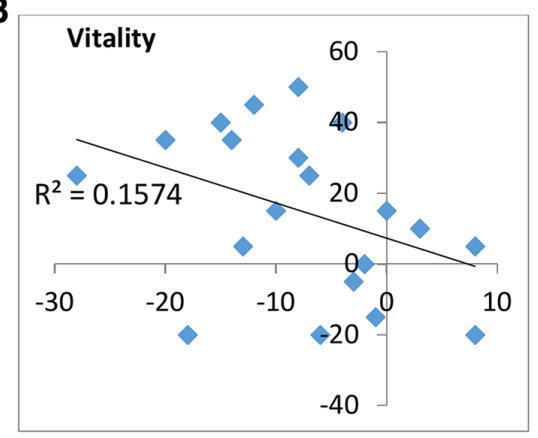

C

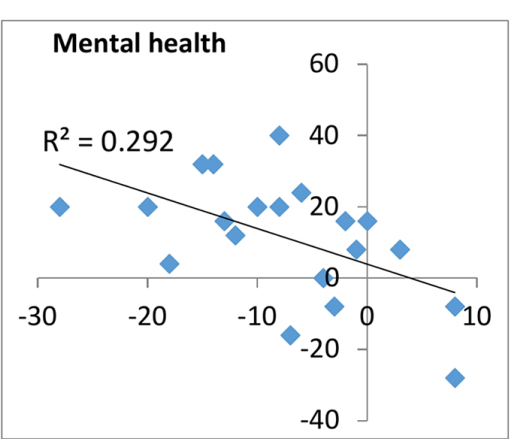

G

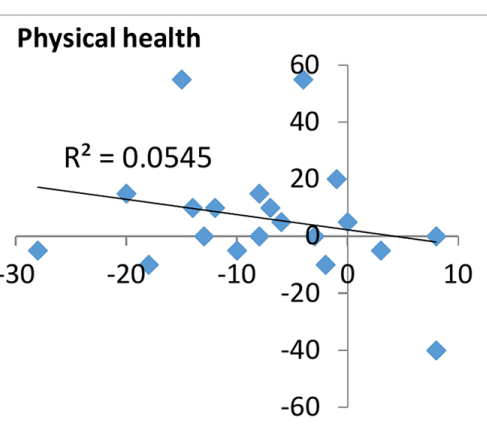

H

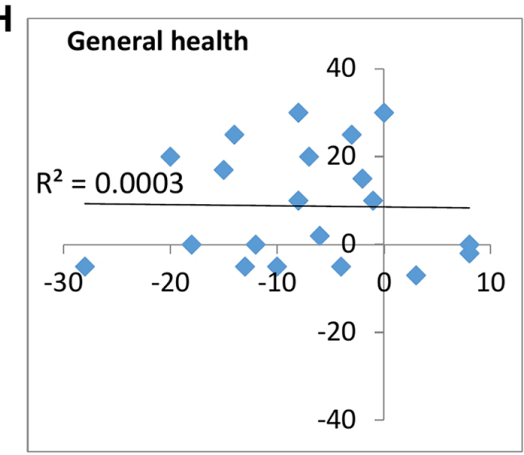

D

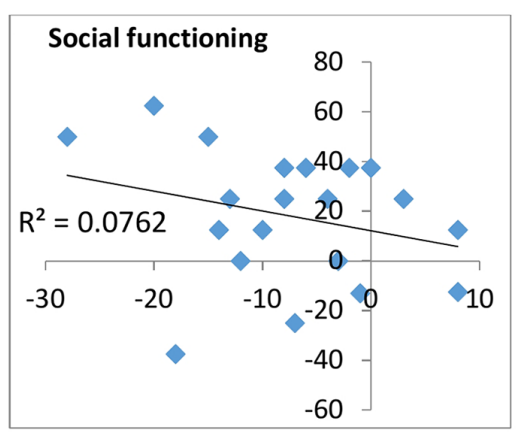

E

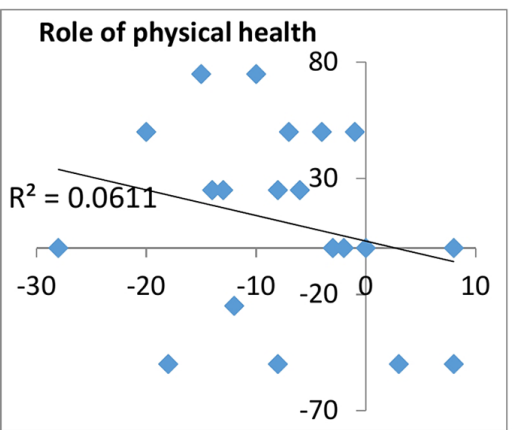

F

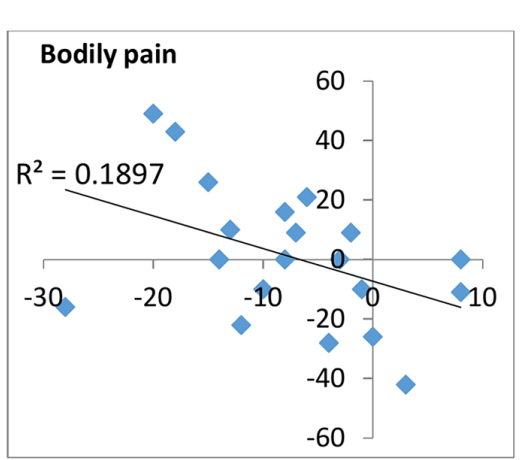

Figure 1 Change in BDI scores plotted against change in health-related quality of life subscale scores from preassessment to postassessment. BDI change score is plotted on the horizontal axis, and the SF-36 change score is plotted on the vertical axis; the upper left quadrant of each graph represents improvement in both outcomes. Change scores for the following subscales are pictured below: $(A)$ role of emotions in functioning, $(B)$ vitality, $(C)$ mental health, $(D)$ social functioning, (E) role of physical health in functioning, $(F)$ bodily pain, $(G)$ physical health and $(H)$ general health. BDI, Beck Depression Inventory; SF-36, 36-Item Short Form Survey.

Many participants in the running group chose not to participate in the study. Low recruitment of patients with mental illness as well as high dropout rates are well-documented limitations in these clinical populations. ${ }^{67}$ Further, we did not have someone available at all times to meet potential participants, which impacted our ability to take advantage of clinic visits. Therefore, the length of time to recruit this sample is consistent with the literature. However, considering we do report some differences in the dropouts compared with those who completed the study (although not for patients who chose not to participate), we should be cautious about 
generalising these findings to all patients with difficultto-treat mood disorders.

Second, this study sample includes a heterogeneous group of participants with current and past diagnoses of $\mathrm{MDD}$ and $\mathrm{BD}$, and total numbers within each group are too small to investigate the impact of specific clinical diagnosis on outcomes. A third limitation of the current study is the duration of the running intervention. Although the antistress and antidepressant effects of exercise can be detected after as little as one session, ${ }^{68}$ the impact on functional outcomes in mood disorders may lag behind improvements in mood symptoms. ${ }^{14}$ For example, visual and verbal memory improvements have been reported as detectable between 14 and 28 weeks, ${ }^{69}$ which was beyond the observation period in this study.

\section{Future research}

Social isolation is well known to contribute to cognitive dysfunction, in particular on measures of executive functioning ${ }^{70}$ suggesting a large, randomised controlled trial with several comparison groups (eg, high-intensity exercise, low-intensity exercise, exercise alone, no exercise comparisons) could help to tease out the effects of perceived social support and different exercise intensities. Given the limited cognitive benefits observed, intervention and assessments should be structured over a longer period of time, at least 6 months, ${ }^{14}$ with interim assessments. Future research should also seek to understand how age and clinical features (eg, illness chronicity, comorbid diagnoses) interact with the effects of groupbased exercise programmes. In particular, the impact of exercise in patients with $\mathrm{BD}$ represents a large knowledge gap in the literature.

\section{CONCLUSIONS}

The results reported here suggest that a structured, group-based exercise programme is associated with benefits in social functioning and HRQOL in youth and adults with complex and/or difficult-to-treat mood disorders. Future investigation regarding the role of clinical history and social functioning on exercise programmes in youth and adults with mood disorders is required urgently.

Acknowledgements We would like to thank the running coach volunteers Jenna Boyd, Lauren Cudney, Beth Kennedy, Kathryn Litke, Anthony Nazarov, Melissa Parlar and Ryan Pyrke. Esther Pauls from the Running Den is also thanked for her assistance with group leadership.

Contributors LK was the primary author and performed the majority of the assessments and all of the data analyses. SB was involved in the design of the study, in particular surrounding cognitive assessments, and provided direction to the analyses, interpretation of findings and writing of the paper. KM, JW and LG assisted with the design of the running programme, recruitment of participants and weekly data collection. BNF was involved with the design of the study, providing advice for data analyses and interpretation and for writing of the manuscript. RS was a co-principal investigator of this study. He was involved in the design of the study and provided guidance surrounding data analyses and interpretation and writing of the manuscript. MM was a co-principal investigator of this study. She was involved in the design of the study, provided directions surrounding clinical assessments, interpretation of the findings and writing of the manuscript. All authors read and approved the final manuscript.
Funding St Joseph's Healthcare Hamilton Foundation provided funding to support this study; specifically, we wish to acknowledge the following donors: Ontario Endowment for Children \& Youth in Recreation Fund at the Hamilton Community Foundation, Canadian Tire Financial Services, FGL Sports, Telus, and Jackman Foundation.

\section{Competing interests None declared.}

Patient consent for publication Not required.

Ethics approval This study was reviewed and approved by the Hamilton Integrated Research Ethics Board (HIREB) (reference number 12-3660). Informed consent was obtained from all participants included in this study.

Provenance and peer review Not commissioned; externally peer reviewed.

Data availability statement No data are available.

Open access This is an open access article distributed in accordance with the Creative Commons Attribution Non Commercial (CC BY-NC 4.0) license, which permits others to distribute, remix, adapt, build upon this work non-commercially, and license their derivative works on different terms, provided the original work is properly cited, appropriate credit is given, any changes made indicated, and the use is non-commercial. See: http://creativecommons.org/licenses/by-nc/4.0/.

\section{REFERENCES}

1. World Health Organization. The Global Burden of Disease: 2004 Update. Geneva, Switzerland: World Health Organization, 2008.

2. Pearson C, Janz T, Ali J. Mental and substance use disorders in Canada. statistics Canada, 2013. Available: https://www150.statcan gc.ca/n1/en/pub/82-624-x/2013001/article/11855-eng.pdf?st= 8Mq0pyEK [Accessed 6 Jun 2018].

3. Mcdonald KC, Bulloch AGM, Duffy A, et al. Prevalence of bipolar I and II disorder in Canada. Can J Psychiatry 2015;60:151-6.

4. World Health Organization. Depression and other common mental disorders: global health estimates. Geneva, Switzerland, 2017.

5. Keller MB, Lavori PW, Mueller TI, et al. Time to recovery, chronicity, and levels of psychopathology in major depression. A 5-year prospective follow-up of 431 subjects. Arch Gen Psychiatry 1992;49:809-16.

6. National Collaborating Centre for Mental Health. Bipolar disorder: The management of bipolar disorder in adults, children and adolescents, in primary and secondary care. London, UK: The British Psychological Society and the Royal College of Psychiatrists, 2006

7. Kolovos S, van Tulder MW, Cuijpers P, et al. The effect of treatment as usual on major depressive disorder: a meta-analysis. J Affect Disord 2017;210:72-81.

8. Kennedy SH, Lam RW, Mclntyre RS, et al. Canadian network for mood and anxiety treatments (CANMAT) 2016 clinical guidelines for the management of adults with major depressive disorder. Can J Psychiatry 2016;61:540-60.

9. Yatham LN, Kennedy SH, Parikh SV, et al. Canadian network for mood and anxiety treatments (CANMAT) and International Society for bipolar disorders (ISBD) collaborative update of CANMAT guidelines for the management of patients with bipolar disorder: update 2013. Bipolar Disord 2013;15:1-44.

10. Trivedi MH, Rush AJ, Wisniewski SR, et al. Evaluation of outcomes with citalopram for depression using measurement-based care in $\mathrm{STAR}^{\star} \mathrm{D}$ : implications for clinical practice. Am J Psychiatry 2006;163:28-40.

11. Kaya E, Aydemir O, Selcuki D. Residual symptoms in bipolar disorder: the effect of the last episode after remission. Prog Neuropsychopharmacol Biol Psychiatry 2007;31:1387-92.

12. MacQueen GM, Memedovich KA. Cognitive dysfunction in major depression and bipolar disorder: assessment and treatment options. Psychiatry Clin Neurosci 2017;71:18-27.

13. Martínez-Arán A, Vieta E, Torrent $C$, et al. Functional outcome in bipolar disorder: the role of clinical and cognitive factors. Bipolar Disord 2007;9:103-13.

14. Lam RW, Parikh SV, Michalak EE, et al. Canadian network for mood and anxiety treatments (CANMAT) consensus recommendations for functional outcomes in major depressive disorder. Ann Clin Psychiatry 2016;27:142-9.

15. Sigwalt AR, Budde $\mathrm{H}$, Helmich I, et al. Molecular aspects involved in swimming exercise training reducing anhedonia in a rat model of depression. Neuroscience 2011;192:661-74.

16. Duman $\mathrm{CH}$, Schlesinger L, Russell DS, et al. Voluntary exercise produces antidepressant and anxiolytic behavioral effects in mice. Brain Res 2008;1199:148-58.

17. Van der Borght K, Havekes R, Bos T, et al. Exercise improves memory acquisition and retrieval in the $\mathrm{Y}$-maze task: relationship with hippocampal neurogenesis. Behav Neurosci 2007;121:324-34. 
18. van Praag $\mathrm{H}$, Shubert $\mathrm{T}$, Zhao $\mathrm{C}$, et al. Exercise enhances learning and hippocampal neurogenesis in aged mice. J Neurosci 2005;25:8680-5

19. Josefsson T, Lindwall M, Archer T. Physical exercise intervention in depressive disorders: meta-analysis and systematic review. Scand $J$ Med Sci Sports 2014;24:259-72.

20. Salagre E, Solé B, Tomioka Y, et al. Treatment of neurocognitive symptoms in unipolar depression: a systematic review and future perspectives. J Affect Disord 2017;221:205-21.

21. Asher GN, Gartlehner G, Gaynes BN, et al. Comparative benefits and harms of complementary and alternative medicine therapies for initial treatment of major depressive disorder: systematic review and meta-analysis. J Altern Complement Med 2017;23:907-19.

22. Möller H-J. Outcomes in major depressive disorder: the evolving concept of remission and its implications for treatment. World J Biol Psychiatry 2008;9:102-14.

23. IsHak WW, Greenberg JM, Balayan K, et al. Quality of life: the ultimate outcome measure of interventions in major depressive disorder. Harv Rev Psychiatry 2011;19:229-39.

24. Mather AS, Rodriguez C, Guthrie MF, et al. Effects of exercise on depressive symptoms in older adults with poorly responsive depressive disorder: randomised controlled trial. Br J Psychiatry 2002;180:411-5

25. Doyne EJ, Ossip-Klein DJ, Bowman ED, et al. Running versus weight lifting in the treatment of depression. $J$ Consult Clin Psychol 1987;55:748-54.

26. Veale D, Le Fevre K, Pantelis C, et al. Aerobic exercise in the adjunctive treatment of depression: a randomized controlled trial. $J$ $R$ Soc Med 1992;85:541-4

27. Greer TL, Trombello JM, Rethorst CD, et al. Improvements in psychosocial functioning and health-related quality of life following exercise augmentation in patients with treatment response but nonremitted major depressive disorder: results from the TREAD study. Depress Anxiety 2016;33:870-81.

28. Malhi GS, Byrow Y. Exercising control over bipolar disorder. Evid Based Mental Health 2016;19:103-5.

29. Keating LE, Becker S, McCabe K, et al. Effects of a 12-week running programme in youth and adults with complex mood disorders. BMJ Open Sport Exerc Med 2018;4.

30. Canadian Society for Exercise Physiology. PAR-Q \& You: $A$ Questionnaire for People Aged 15 to 692002

31. Delis DC, Kramer JH, Kaplan E, et al. California verbal learning Test ${ }^{\circledR}$ -. Second Edition (CVLT® -II). San Antonio, TX: The Psychological Corporation, 2000.

32. Wechsler D. Wechsler adult intelligence scale -. Fourth Edition (WAIS-IV). San Antonio, TX: Pearson, 2008.

33. Reynolds CR. Forward and backward memory span should not be combined for clinical analysis. Arch Clin Neuropsychol 1997;12:29-40.

34. Stroop JR. Studies of interference in serial verbal reactions. J Exp Psychol 1935;18:643-62.

35. Kirwan CB, Stark CEL. Overcoming interference: an fMR investigation of pattern separation in the medial temporal lobe. Learn Mem 2007;14:625-33.

36. Becker S. Neurogenesis and pattern separation: time for a divorce. WIREs Cogn Sci 2017;8:e1427 file:///C:/Users/keatingl/Downloads/ BeckerWIRESCogSci2016.pdf

37. Déry N, Goldstein A, Becker S. A role for adult hippocampal neurogenesis at multiple time scales: a study of recent and remote memory in humans. Behav Neurosci 2015;129:435-49.

38. Déry N, Pilgrim M, Gibala M, et al. Adult hippocampal neurogenesis reduces memory interference in humans: opposing effects of aerobic exercise and depression. Front Neurosci 2013;7.

39. Goldstein A, Déry N, Pilgrim M, et al. Stress and binge drinking: a toxic combination for the teenage brain. Neuropsychologia 2016;90:251-60.

40. Heisz JJ, Clark IB, Bonin K, et al. The effects of physical exercise and cognitive training on memory and neurotrophic factors. $J$ Cogn Neurosci 2017;29:1895-907.

41. Shelton DJ, Kirwan CB. A possible negative influence of depression on the ability to overcome memory interference. Behav Brain Res 2013;256:20-6.

42. Yassa MA, Mattfeld AT, Stark SM, et al. Age-related memory deficits linked to circuit-specific disruptions in the hippocampus. Proc Natl Acad Sci U S A 2011;108:8873-8.

43. Becker S, Wojtowicz JM. A model of hippocampal neurogenesis in memory and mood disorders. Trends Cogn Sci 2007;11:70-6.

44. Jacobs BL, van Praag H, Gage FH. Adult brain neurogenesis and psychiatry: a novel theory of depression. Mol Psychiatry 2000;5:262-9.
45. Kempermann G. Regulation of adult hippocampal neurogenesis implications for novel theories of major depression. Bipolar Disord 2002;4:17-33.

46. Sahay A, Hen R. Adult hippocampal neurogenesis in depression. Nat Neurosci 2007:10:1110-5.

47. Beck AT, Steer RA, Brown GK. Manual for the Beck depression inventory. Second Edition (BDI-II). edn. San Antonio, TX: Psychological Corporation, 1996.

48. Beck AT, Epstein N, Brown G, et al. An inventory for measuring clinical anxiety: psychometric properties. J Consult Clin Psychol 1988;56:893-7.

49. Cohen S, Kamarck T, Mermelstein R. A global measure of perceived stress. J Health Soc Behav 1983;24:385-96.

50. Ware JE, Kosinski M, Keller SD. SF-36 physical and mental health summary scales: a users' manual. Boston, MA: Health Assessment Lab, 1994.

51. Ware JE, Sherbourne CD. The mos 36-item short-form health Survey (SF-36). I. conceptual framework and item selection. Med Care 1992;30:473-83

52. Smith PJ, Blumenthal JA, Hoffman BM, et al. Aerobic exercise and neurocognitive performance: a meta-analytic review of randomized controlled trials. Psychosom Med 2010;72:239-52.

53. Rathore A, Lom B. The effects of chronic and acute physical activity on working memory performance in healthy participants: a systematic review with meta-analysis of randomized controlled trials. Syst Rev 2017;6.

54. Stroth S, Hille K, Spitzer M, et al. Aerobic endurance exercise benefits memory and affect in young adults. Neuropsychol Rehabil 2009:19:223-43

55. MacQueen GM, Campbell S, McEwen BS, et al. Course of illness, hippocampal function, and hippocampal volume in major depression. Proceedings of the National Academy of Sciences 2003;100:1387-92

56. McKinnon MC, Yucel K, Nazarov A, et al. A meta-analysis examining clinical predictors of hippocampal volume in patients with major depressive disorder. Psychiatry Neurosci 2009;34:41-54.

57. Campbell S, Marriott M, Nahmias C, et al. Lower hippocampal volume in patients suffering from depression: a meta-analysis. AJP 2004;161:598-607.

58. Videbech P, Ravnkilde B. Hippocampal volume and depression: a meta-analysis of MRI studies. Am J Psychiatry 2004;161:1957-66.

59. Brondino N, Rocchetti M, Fusar-Poli L, et al. A systematic review of cognitive effects of exercise in depression. Acta Psychiatr Scand 2017;135:285-95.

60. Guiney H, Machado L. Benefits of regular aerobic exercise for executive functioning in healthy populations. Psychon Bull Rev 2013;20:73-86.

61. Diamond A. Effects of physical exercise on executive functions: going beyond simply moving to moving with thought. Ann Sports Med Res 2015;2.

62. Gómez-Pinilla F, Hillman C. The influence of exercise on cognitive abilities. Compr Physiol 2013;3:403-28.

63. Mota-Pereira J, Carvalho S, Silverio J, et al. Moderate physical exercise and quality of life in patients with treatment-resistant major depressive disorder. J Psychiatr Res 2011;45:1657-9.

64. Carta M, Hardoy M, Pilu A, et al. Improving physical quality of life with group physical activity in the adjunctive treatment of major depressive disorder. Clin Pract Epidemiol Ment Health 2008:4.

65. Schuch FB, Vancampfort D, Rosenbaum S, et al. Exercise improves physical and psychological quality of life in people with depression: a meta-analysis including the evaluation of control group response. Psychiatry Res 2016;241:47-54.

66. Hearing CM, Chang WC, Szuhany KL, et al. Physical exercise for treatment of mood disorders: a critical review. Curr Behav Neurosci Rep 2016;3:350-9.

67. Brown JSL, Murphy C, Kelly J, et al. How can we successfully recruit depressed people? Lessons learned in recruiting depressed participants to a multi-site trial of a brief depression intervention (the 'CLASSIC' trial). Trials 2019;20.

68. Pretty J, Peacock J, Sellens M, et al. The mental and physical health outcomes of green exercise. Int $J$ Environ Health Res 2005;15:319-37.

69. Herrera-Guzmán I, Gudayol-Ferré E, Herrera-Abarca JE, et al. Major depressive disorder in recovery and neuropsychological functioning: effects of selective serotonin reuptake inhibitor and dual inhibitor depression treatments on residual cognitive deficits in patients with major depressive disorder in recovery. $J$ Affect Disord 2010;123:341-50.

70. Cacioppo JT, Hawkley LC. Perceived social isolation and cognition. Trends Cogn Sci 2009;13:447-54. 